\title{
AS TENDÊNCIAS PEDAGÓGICAS E AS PRÁTICAS EDUCATIVAS NA SAÚDE
}

\author{
Tatiana Sá MENEZES* \\ Ana Paula Sá MENEZES**
}

\begin{abstract}
* Acadêmica do curso de Enfermagem da Universidade Federal de Roraima, Boa Vista, RR. E-mail: tatty_sm@hotmail.com
\end{abstract}

** Mestre em Ensino de Ciências na Amazônia. Chefe da Divisão de Pesquisa do Museu Integrado de Roraima. Professora do curso de Enfermagem da Faculdade Roraimense de Ensino Superior, Boa Vista, RR, na disciplina de Educação para a Saúde. E-mail: ana-p_sa@hotmail.com

Recebido em: 30/05/2014 - Aprovado em: 18/09/2014 - Disponibilizado em: 15/12/2014

RESUMO: A Organização Mundial de Saúde (OMS) define a saúde como um estado de completo bem-estar físico, mental e social e não somente ausência de afecções e enfermidades. Problemas como gravidez indesejada na adolescência, AIDS, violência contra a mulher, doenças tropicais, falta de saneamento básico, são alguns dos problemas que têm grandes consequências na saúde. Entretanto, percebe-se que a educação é um instrumento poderoso para romper o ciclo de pobreza, doenças e violência e que a escola é um campo imprescindível ao desenvolvimento de projetos de saúde coletiva. Porém, é necessário um conhecimento pedagógico por parte dos profissionais da Saúde sobre quais tendências podem e devem ser utilizadas na elaboração de projetos de intervenção de promoção de saúde em escolas. O objetivo da pesquisa foi analisar qual seria a tendência pedagógica mais profícua para se promover a Educação em Saúde em comunidades escolares a partir de discursos existentes, permitindo um posicionamento frente a eles, bem como uma verificação de sua sustentabilidade a partir de conceitos utilizados por pesquisadores de Saúde Coletiva e de Educação. As tendências pedagógicas analisadas foram: liberal (tradicional, escola nova e tecnicista) e progressista (libertária, libertadora e histórico-crítico-social dos conteúdos). A pesquisa foi bibliográfica, exploratória e analítica. Conclui-se que as propostas educacionais baseadas na reflexão, na crítica e na conscientização do indivíduo enquanto cidadão, ou seja, as progressistas, são as mais propícias quando se fala em implantar novos projetos educativos na promoção da saúde.

PALAVRAS-CHAVE: Educação em Saúde. Tendências Pedagógicas Liberais. Tendências Pedagógicas Progressistas. Conceito de Educação em Saúde. Enfermagem.

\begin{abstract}
The World Health Organization defines health as a state of complete physical wellbeing, mental and social and not only absence of disease and infirmity. Problems in adolescence as unwanted pregnancy, AIDS, violence against women, tropical diseases, lack of basic sanitation, are some of the problems that has major consequences in health. However, one realizes that education is a powerful tool for breaking the cycle of poverty, disease and violence and school and a field development project essential collective health. However, you need pedagogic a knowledge by the health professionals about what trends and can be used in drafting of promotion intervention health in schools. The aim was examine what would be the trend pedagogical more fruitful to promote health education in school communities from speeches existing position allowing a face to them, and a check of your sustainability from concepts used by researchers health education and collective. Pedagogical trends analyzed were: liberal (traditional and new school Technicist) and progressive (libertarian, releasing and critical history-social-contents). A search was literature, exploratory and analytic. Concludes that the proposals based educational reflection, critique and awareness of individual citizen, that is, the progressive, are more propitious when talking to implement new projects in education in health promotion.
\end{abstract}


KEYWORDS: Health Education. Trends Pedagogical Liberals. Progressive Educational Trends. Concept of Health Education. Nursing.

\section{INTRODUÇÃo}

Vive-se num mundo de transformações muito rápidas e isso exige da educação contínuas adaptações e estratégias que possam intervir de maneira satisfatória aos problemas que essas mudanças estão gerando. Apesar de tantas inovações tecnológicas e descobertas no campo científico, como a criação da vida em laboratório, muitos problemas do século passado teimam em continuar. A falta de qualidade do sistema público de saúde e a escassez de médicos é um deles. Outro indicador muito importante para a análise do Índice de Desenvolvimento Humano (IDH) é a mortalidade infantil, que corresponde ao número de crianças que vão a óbito antes de atingir um ano de idade. No Brasil, as taxas de mortalidade infantil diminuíram muito nas duas últimas décadas, no entanto, o índice continua muito elevado, cerca de 23,6 mortes para cada mil nascimentos (1).

A cada dia que passa, a sociedade se encontra ante novas questões e desafios. Os agentes epidemiológicos, foram substituído em alguns países por uma série de doenças infecciosas (cólera, malária, diarreia infantil), outras patologias como doenças crônicas (cardiovasculares, câncer) e as chamadas mal do século: AIDS, alcoolismo, vício em drogas, estresse e depressão. Estas doenças crônicas possuem critérios de vulnerabilidade, uma vez que muitas delas compartilham vários fatores de risco como tabagismo, consumo excessivo de álcool, hipertensão, má alimentação, obesidade e inatividade física são comuns a muitas destas doenças. Com essas novas doenças, adentra-se em uma nova etapa na história da Saúde Pública, na qual os problemas de saúde da população vão além dos campos tradicionais da medicina para a prevenção e exigem um tratamento educacional. Por isso, convém assinalar a complexidade que está se vivendo e a importância de se definir conceitualmente Educação em Saúde e/ou Saúde Coletiva.

Em toda sociedade, os processos de mudança a nível macro são permanentemente associados aos processos que envolvem os indivíduos em sua prática diária (nível micro). Nesse sentido, a Educação em Saúde é importante, quando se pensa na educação e formação dos profissionais de saúde. Outrossim, como profissional da área de Saúde, o enfermeiro não pode esquecer o lado holístico do ser humano e todas as suas facetas. Daí a importância de se conhecer que tendências pedagógicas são mais apropriadas para se falar em prevenção, saúde e qualidade de vida nas escolas. 
O objetivo da pesquisa foi analisar qual seria a tendência pedagógica mais profícua para se promover a Educação em Saúde em comunidades escolares a partir de discursos existentes, permitindo um posicionamento frente a eles, bem como uma verificação de sua sustentabilidade a partir de conceitos utilizados por pesquisadores de Saúde Coletiva e de Educação. As tendências pedagógicas analisadas foram: liberal (tradicional, escola nova e tecnicista) e progressista (libertária, libertadora e históricocrítico-social dos conteúdos). A pesquisa foi bibliográfica, exploratória e analítica. É voltada para acadêmicos, professores e profissionais da área de saúde.

\section{DESENVOLVIMENTO}

\subsection{O CONCEITO DE EDUCAÇÃO EM}

\section{SAÚDE}

A definição do significado de Educação requer uma tarefa anterior: estabelecer as suas características diferenciais. Para se definir o objeto de estudo da Educação em Saúde, fazse necessário definir o que é Educação. Uma definição inadequada de Educação, levar-nosia a uma definição inadequada de Educação em Saúde.

A etimologia da palavra educação tem origem no latim e transporta diferentes significados. Tem origem latina: educatio, sinônimo de ação de criar ou de nutrir, cultura, cultivo.
Designa um ato ou um processo e um efeito. Educação, ao mesmo tempo, significa o ato ou processo de educar ou educar-se e o conhecimento e desenvolvimento resultantes desse ato ou processo.

Para Amorim (s.d., p. 1113), "alguém que educa e alguém que é educado estão unidos pela palavra educação, sendo que é possível a uma pessoa educar a si mesma, ou seja, ser educador e educando de uma só vez, por exemplo, a partir da observação, enfim, da experiência da vida social".

A Educação abrange os processos formativos que se desenvolvem na vida familiar, na convivência humana, no trabalho, nas instituições de ensino e pesquisa, nos movimentos sociais e organizações da sociedade civil e nas manifestações culturais (BRASIL, 1996). A escola deve proporcionar formação integral (intelectual, afetiva e social) às crianças, pois o desenvolvimento intelectual envolve muito mais do que um simples cérebro.

Para Arroyo (1993, apud QUESADA, 2004, p. 6), a educação está pautada na intencionalidade:

— Intencionalidad del agente educador: se interpreta la educación ante todo como heteroeducación y se asigna al educador la intencionalidad en su actuación.

— Intencionalidad en el educando: en éste se sitúan la conciencia y la intencionalidad propias de la educación.

- Intencionalidad en el educador y en el educando: restringe la noción de educación, no tendría sentido 
designar por educación la influencia madre-hijo o la autoeducación en sentido estricto.

- Intencionalidad no explícita: la educación es proceso o desarrollo, o influencia que produce o genera un efecto determinado de ordinario estimado como deseable.

Saviani (1996, p. 120) entende educação como

Um processo que se caracteriza por uma atividade mediadora no seio da prática social global. Tem-se pois, como premissa básica que a educação está sempre referida a uma sociedade concreta, historicamente situada. [...] Como atividade mediadora, a educação se situa em face das demais manifestações sociais em termos de ação recíproca. A fim de determinar o tipo de ação exercida pela educação sobre diferentes setores da sociedade, bem como o tipo de ação que sofre das demais forças sociais. É preciso para cada sociedade, examinar as manifestações fundamentais e derivadas, as contradições primárias e secundárias.

Educação, na sua especificidade, é uma prática social voltada para a formação da pessoa na sua totalidade. Sua ação é intencional e busca impulsionar o crescimento interpessoal e formação da pessoa humana.

A Educação para a Saúde deve estar envolvida na vida das pessoas, considerandose uma multiplicidade de aspectos, desde aqueles relacionados a cuidar do corpo e da mente com a percepção dos bens coletivos produzidos pela sociedade, que os cidadãos podem e devem usufruir, e a luta por esses direitos.

A Educação para a Saúde é uma prática social concreta, que é estabelecida entre certas pessoas - profissionais e usuários -, para atuar nas instituições, em busca de autonomia, capaz de escolher e tomar decisões, considerando valores éticos de justiça, solidariedade, produtividade e equidade, agindo como educadores em relação ao outro (indivíduo, grupo, comunidade).

A Saúde Coletiva pode ser considerada o campo do conhecimento científico de natureza interdisciplinar que "tiene como objeto las necesidades sociales de la salud; como instrumentos de trabajo los distintos conocimientos, disciplinas, tecnologías materiales $y$ no materiales; $y$, como actividades las intervenciones centradas en los grupos sociales y en el ambiente" (PAIM, 2000 apud VILA; VILA, 2007). Consiste na "arte y la ciencia de prevenir la enfermedad y la incapacidad; prolongar la vida y promover la salud física y mental mediante los esfuerzos organizados de la comunidad" (BARRETO, 2003 apud VILA; VILA, 2007). No Brasil, este campo do conhecimento tem como referência a promoção da saúde e a prevenção de doeças com o objetivo de oferecer uma melhor qualidade de vida à população.

Entre as atividades do Enfermeiro, a Educação em Saúde deve ser uma prioridade, especialmente em comunidades carentes e/ou desprovidas de recursos. O Enfermeiro é habilitado e capacitado para cuidar dos pacientes e de sua família, assisti-los em todas as suas dimensões existenciais, levando em consideração as necessidades de cura, preventiva e educativas dos cuidados em saúde. 
Logo, a promoção da saúde está situada dentro de um novo paradigma que engloba uma série de ações para a população, serviços de saúde e outros serviços sociais, e também considera a importância da satisfação das necessidades básicas da pessoa, juntamente com outras nobres aspirações. E a escola é um local de suma importância, pois se acha num dos contextos principais para o desenvolvimento de atividades de Saúde Coletiva, já que intervém diariamente com pessoas de todas as idades e níveis, que, por isso, possuem uma grande diversidade de hábitos e de capacidade de aprendizagem e

\subsection{AS TENDÊNCIAS PEDAGÓGICAS E A} EDUCACAO EM SAÚDE

Luckesi (1990) relaciona educação e sociedade e afirma que a "Pedagogia se delineia a partir de uma posição filosófica definida”. Este autor apresenta três tendências filosóficas responsáveis por interpretar a função da educação na sociedade: a Educação Redentora, a Educação Reprodutora e a Educação Transformadora da sociedade. A primeira é otimista, acredita que a educação pode exercer domínio sobre a sociedade (pedagogias liberais). A segunda é pessimista, percebe a educação como sendo apenas reprodutora de um modelo social vigente, enquanto a terceira tendência assume uma postura crítica com relação às duas anteriores, indo de encontro tanto ao otimismo ilusório assimilação para um desenvolvimento saudável.

Para Vila e Vila (2007)

La educación en salud es comprendida como un medio de intercambiar informaciones y de desarrollar una visión crítica de los problemas de la salud y no como un proceso limitado de transformación de informaciones; se puede concebir como un hecho social, que integra factores y aspectos subjetivos; también se puede considerar como una práctica social, porque es actitud, es actuación, es vivencia, es algo que ocurre a cada instante.

A Educação em Saúde deve ter como objeto de preocupação todos os membros da sociedade.

quanto ao pessimismo imobilizador (Pedagogias Progressivistas).

Para Libâneo (2006, p. 21), as principais Tendências Pedagógicas usadas na educação brasileira se dividem em duas grandes linhas de pensamento pedagógico: Tendências Liberais e Tendências Progressistas.

\subsubsection{Tendências Liberais}

A Pedagogia Liberal é também denominada de acrítica, pois não questiona a implicação dos determinantes socioestruturais da educação, compreendendo o fenômeno educativo nele mesmo (LIBÂNEO, 2006). Não tem a ver com algo aberto ou democrático, mas com uma instigação da sociedade capitalista ou sociedade de classes, 
que sustenta a ideia de que o aluno deve ser preparado para papéis sociais de acordo com as suas aptidões, aprendendo a viver em harmonia com as normas desse tipo de sociedade, tendo uma cultura individual. Divide-se em quatro escolas: Tradicional, Renovadora Progressiva, Renovadora não Diretiva (Escola Nova) e Tecnicista.

Tradicional: Foi a primeira a ser instituída no Brasil, pelos jesuítas, por motivos históricos. De acordo com esta tendência, a atuação da escola deve consistir na preparação intelectual, cultural e moral dos alunos para que eles assumam sua posição na sociedade. Baseia-se na relação hierárquica do professor

\section{Renovadora não diretiva (Escola Nova):}

Anísio Teixeira foi o grande pioneiro da Escola Nova no Brasil. É um método centrado no aluno. Prega a educação como tendo uma função de adaptação à vida, pela correspondência entre necessidades e interesses individuais com as exigências da sociedade. Modifica-se o sistema de orgnização escolar (adota-se o trabalho em grupo, multiplicam-se os testes de inteligência e os ocupacionais). O professor já não é o que ensina mas o que facilita a aprendizagem (LIBÂNEO, 2006).

Tecnicista: Prega a racionalidade e a produtividade do sistema e do trabalho do professor. A ênfase é nos meios (técnicas de ensino). Subordina a educação à sociedade, em relação aos alunos. Nesta tendência o professor é a figura central e o aluno é um receptor passivo dos conhecimentos considerados como verdades absolutas. Há repetição de exercícios com exigência de memorização, ou seja, no ensino tradicional, o ensino é centralizado no professor e os alunos são meros receptores (FOGAÇA, 2012).

Renovadora Progressiva: Acentua o sentido da cultura como desenvolvimento das aptidões individuais. Propõe um ensino que valorize a autoeducação (o aluno como sujeito do conhecimento), a experiência direta sobre o meio pela atividade, um ensino centrado no aluno e no grupo (LIBÂNEO, 2006).

tendo como função a preparação de mão de obra para a indústria. A sociedade industrial e tecnológica estabelece as metas econômicas sociais e políticas. A educação treina os alunos para um comportamento de ajuste a essas metas. Utiliza-se basicamente do enfoque sistêmico, da tecnologia educacional e da análise experimental do comportamento (LIBÂNEO, 2006).

\subsubsection{Tendências Progressistas}

Partem de uma análise crítica das realidades sociais, sustentam implicitamente as finalidades sociopolíticas da educação e é uma tendência que condiz com as ideias implantadas pelo capitalismo. O desenvolvimento e popularização da análise 
marxista da sociedade possibilitou o desenvolvimento da tendência progressista, que se ramifica em três correntes: Libertadora, Libertária e Histórico-críticasocial-dos-conteúdos.

Libertadora: Também conhecida como a pedagogia de Paulo Freire, essa tendência vincula a educação à luta e organização de classe do oprimido. Onde, para esse, o saber mais importante é a de que ele é oprimido, ou seja, ter uma consciência da realidade em que vive. Além da busca pela transformação social, a condição de se libertar através da elaboração da consciência crítica passo a passo com sua organização de classe. Centraliza-se na discussão de temas sociais e políticos; o professor coordena atividades e atua juntamente com os alunos (FOGAÇA, 2012).

Libertária: Procura a transformação da personalidade num sentido libertário e autogestionário. Entendendo a autogestão como a única forma de democracia efetiva, idealizam-na enquanto ação direta a partir de uma consciência de classe que visasse à emancipação dos trabalhadores. É justamente neste aspecto que se estreitam os laços entre a vontade revolucionária e uma pedagogia fundamentada no princípio da liberdade. Parte do pressuposto de que somente o vivido pelo educando é incorporado e utilizado em situações novas, por isso o saber sistematizado só terá relevância se for possível seu uso prático. Enfoca a livre expressão, o contexto cultural, a educação estética. Os conteúdos, apesar de disponibilizados, não são exigidos pelos alunos e o professor é tido como um conselheiro à disposição do aluno (FOGAÇA, 2012; KASSICK, 2008)

\section{Crítico-social dos conteúdos ou Histórico-}

Crítica: Trata-se de uma pedagogia que leva em conta os determinantes sociais e que propicia a crítica dos mecanismos e imposições resultantes da organização da sociedade em classes sociais antagônicas. Ao mesmo tempo, é uma pedagogia que vai buscar no interior da escola respostas pedagógico-didáticas que permitam o exercício dessa crítica, a partir das próprias determinações sociais das situações pedagógicas concretas (LIBÂNEO, 2006).

Segundo Machado e Wanderley (2012, p. 6), "a escolha da abordagem pedagógica adequada está vinculada ao objetivo da ação educativa”. Logo, o profissional da Saúde, antes de realizar qualquer projeto de intervenção, deve ter em mente que tipo de ação quer ver realizada. Se quer a transmissão de algum conhecimento técnico específico para seus Agentes Comunitários de Saúde, por exemplo, poderá se utilizar das tendências liberais. Diferentemente, um enfermeiro que queira uma mudança 
(transformação, quebra paradigmática) no entorno de sua comunidade, deverá sempre ter seus projetos construídos com base nas tendências progressistas.

A OMS define a saúde como um estado de completo bem-estar físico, mental e social e não somente ausência de afecções e enfermidades. Problemas como gravidez indesejada na adolescência, AIDS, violência contra a mulher, doenças tropicais, falta de saneamento básico, são alguns dos problemas que têm grandes consequências na saúde. Entretanto, percebe-se que a educação é um instrumento poderoso para romper o ciclo de pobreza, doenças e violência e que a escola é um campo imprescindível ao desenvolvimento de projetos de saúde coletiva. Porém, é necessário um conhecimento pedagógico por parte dos profissionais da Saúde sobre quais tendências podem e devem ser utilizadas na elaboração de projetos de intervenção de promoção de saúde em escolas. Nesse sentido, é importante notar que não existe dicotomia entre os conceitos de Educação e de Saúde, pois ambas estão em uma relação dialética e articulada, contribuindo para a integralidade do ser humano. Essa integralidade deve estar pautada nos quatro pilares da educação definidos por Delors (2010): aprender a conhecer, aprender a fazer, aprender a conviver e aprender a ser.

\subsection{METODOLOGIA}

Quanto aos objetivos, a pesquisa foi do tipo exploratória, pois segundo Ciribelli (2003, p. 54), "proporciona maiores informações sobre o tema que o pesquisador pretende abordar; auxilia-o a delimitá-lo; ajuda-o a definir seus objetivos e a formular suas hipóteses de trabalho e também a descobrir uma forma original de desenvolver o seu assunto".

Quanto aos meios ou procedimentos pelo qual se obtém os dados, a pesquisa foi do tipo bibliográfica, pois foi baseada em livros e artigos. Enquanto trabalho autônomo, a pesquisa bibliográfica compreende várias fases, que vão da escolha do tema à redação final. O delineamento da presente pesquisa (bibliográfica) foi feito de acordo com as seguintes etapas (GIL, 2010):

Escolha do tema: o tema foi escolhido no intuito de elucidar qual a tendência pedagógica que mais se adequa em projetos na promoção de saúde nas escolas.

Levantamento bibliográfico: foi realizado o levantamento da produção científica com a temática Educação em Saúde existente em periódicos indexados e se definiu como critério de inclusão o conceito de educação e as tendências pedagógicas no Brasil.

Formulação do problema: deu-se no intuito de elucidar sobre qual a tendência pedagógica que mais se adequa em projetos na promoção de saúde nas escolas. 
Leitura do material: leitura seletiva e analítica, a partir de discursos existentes, permitindo um posicionamento frente a eles, bem como uma verificação de sua sustentabilidade a partir de conceitos utilizados por pesquisadores de Saúde Coletiva e de Educação.

Redação do texto: artigo de revisão.

\section{CONSIDERAÇÕES}

As tendências pedagógicas são extremamente relevantes para a Educação em Saúde, pois contribuem para a melhor condução do trabalho do enfermeiro em seus projetos de Saúde Coletiva, baseado nas demandas atuais da comunidade escolar. O conhecimento dessas tendências e onde aplicá-las na Educação em Saúde por parte dos profissionais de saúde, especialmente dos Enfermeiros, é fundamental para o sucesso de projetos de Promoção à Saúde na Escola, pois a escolha de uma tendência deve estar relacionada ao público alvo planejado. Sendo assim, o conhecimento dessas correntes pedagógicas por parte dos Enfermeiros, tornase de extrema relevância, visto que possibilitam um aprofundamento maior sobre as variáveis do processo de ensinoaprendizagem, direcionando o plano de trabalho a partir de convicções pessoais, profissionais, políticas e sociais, contribuindo para a produção de uma prática estruturada, significativa, esclarecedora e, principalmente, interessante para os educandos.

Dentre as tendências pesquisadas a que melhor se encaixa em projetos de Saúde Coletiva - Promoção de Saúde -, é a tendência Progressista.

A escolha pela tendência Libertária, por exemplo, deve-se ao fato de a mesma partir do pressuposto de que somente o vivido pelo educando é incorporado e utilizado em situações novas, por isso o saber sistematizado só terá relevância se for possível seu uso prático. Quando se fala de Educação Sexual, por exemplo, deve-se abordar primeiramente sobre o que ele sabe, sobre como tema é abordado na escola e na família e como esse ensinamento formal será usado em sua vida. A Educação em Saúde tem como objetivo incentivar a participação da comunidade nos programas de saúde, incluir políticas públicas promover transformações conceituais e na compreensão da saúde, relacionar propostas libertadoras comprometidas com o desenvolvimento da cidadania orientando-se por ações cuja essência está na melhoria da qualidade de vida.

Outra tendência que pode ser usada é a Histórico-Crítica, pois é uma pedagogia que vai buscar no interior da escola respostas pedagógico-didáticas que permitam o exercício dessa crítica, a partir das próprias 
determinações sociais das situações pedagógicas concretas. Nesta, o Enfermeiro pode utilizar os próprios conteúdos que os alunos tem nas aulas de Ciências em seus projetos de Promoção à Saúde na Escola. No contexto da enfermagem praticar Educação em Saúde pautada na tendência HistóricoCrítica, é proporcionar ao individuo, condições para que ele mesmo busque, exponha, questione, viva, experimente, acredite.

A prática de Educação em Saúde não é uma tarefa fácil pois exige dedicação e empenho por parte do enfermeiro, mas é uma tarefa

\section{REFERÊNCIAS}

AMORIM, M.A. Por uma História da Educação para além da Escola. Disponível em:

$<$ http://www.faced.ufu.br/nephe/images/arqind-nome/eixo11/complestos/historia.pdf $>$. Acesso em: 29 de jun. 2013.

BRASIL. Lei no 9394/96 - Estabelece as Diretrizes e Bases da Educação Nacional. Disponível em:

<http://www.planalto.gov.br/ccivil_03/leis/19 394.htm>. Acesso em: 29 de jun. 2013.

CIRIBELLI, M.C. Como elaborar uma dissertação de mestrado através da pesquisa científica. Rio de Janeiro: 7Letras, 2003.

DELORS, Jacques (Coord.). Os quatro pilares da educação. In: Educação: um tesouro a descobrir. São Paulo: Cortezo. p. 89-102. Disponível em: <http://unesdoc.unesco.org/images/0010/0010 95/109590por.pdf $>$. Acesso em: 29 de jun. 2013. extremamente prazerosa. A Saúde Coletiva deve ser vista como uma prática social dirigida a comunidade e ao ser humano. $\mathrm{O}$ Enfermeiro está ligado à prática e intervenções educativas pois está, cada vez mais, preparado para desenvolver seu papel de educador. Sabe-se que é necessário novos estudos que contribuam com a implementação de programas educativos que atendam a toda a comunidade e novas investigações relacionadas à Educação em Saúde, pois certamente contribuirão na relação entra a teoria e a prática dos profissionais de saúde.

\section{FOGAÇA, J. Tendências Pedagógicas} Brasileiras. Disponível em: $<$ http://educador.brasilescola.com/trabalhodocente/tendencias-pedagogicasbrasileiras.htm>. Acesso em: 30 de jun. 2013.

GIL, A.C. Como Elaborar Projetos de Pesquisa. São Paulo: Atlas, 2010.

Henri Wallon. Disponível em: $<$ http://educarparacrescer.abril.com.br/aprendi zagem/henri-wallon-307886.shtml>. Acesso em: 30 de jun. 2013.

IDH Brasileiro: Mortalidade Infantil no Brasil. Disponível em: <http://www.brasilescola.com/brasil/idhbrasileiro-mortalidade-

infantil-no-brasil.htm>. Acesso em: 30 de jun. 2013.

KASSICK, C.N. Pedagogia Libertária na História da Educação Brasileira. Revista HISTEDBR On-line, Campinas, n.32, p.136149, dez. 2008. Disponível em: <http://www.histedbr.fae.unicamp.br/revista/e 
dicoes/32/art09_32.pdf>. Acesso em: 30 de jun. 2013.

LIBÂNEO, J.C. Didática. São Paulo: Cortês, 1994.

. Democratização da escola pública.

21. ed. São Paulo: Loyola, 2006.

LUCKESI, C.C. Filosofia da educação. São Paulo: Cortez, 1990.

MACHADO, A.G.M; WANDERLEY, L.C.S. Educação em Saúde. [2012]. Disponível em: $<$ http://www.unasus.unifesp.br/biblioteca_virt ual/esf/2/unidades_conteudos/unidade09/unid ade09.pdf >. Acesso em: 30 de jun. 2013.

QUESADA, R.P. Promoción y Educación para la Salud. [2004]. Disponível em:

<http://www.diazdesantos.es/wwwdat/pdf/SP 0410004052.pdf>. Acesso em: 28 de jun. 2013.

SANTOS, R.F. dos. Tendências Pedagógicas: o que são e para que servem. [2012]. Disponível em:

<http://www.educacaopublica.rj.gov.br/biblio teca/educacao/0327.html>. Acesso em: 28 de jun. 2013.

SAVIANI, D. Educação: do senso comum à consciência filosófica. 11.ed. São Paulo: Autores Associados, 1996.

VILA, A.C.D.; VILA, V.S.C. Tendencias De La Producción Del Conocimiento En La Educación En La Salud En Brasil. Rev Latino-am Enfermagem, v. 15, n. 6, novembro-dezembro. 2007. Disponível em: $<$ http://www.scielo.br/pdf/rlae/v15n6/es_18.p $\mathrm{df}>$. Acesso

em: 28 de jun. 2013.

\section{Notas}

(1) Disponível em: <http://www.brasilescola.com/brasil/i dh-brasileiro-mortalidade-infantil-no- brasil.htm>. Acesso 29/06/2013 às $22 \mathrm{~h} 19 \mathrm{~min}$. 